\title{
O DESVELAR DA ÁFRICA EM CRIAÇÕES ARTÍSTICAS EM LIVROS DIDÁTICOS DE HISTÓRIA DO ENSINO FUNDAMENTAL
}

\author{
T. M. S. G. S. GUIMARÃES* e S. T. ABREU-BERNARDES \\ Instituto Federal de Educação, Ciência e Tecnologia do Rio Grande do Norte \\ taniamarapedagoga@gmail.com*
}

Artigo submetido em outubro/2015 e aceito em fevereiro/2016

DOI: $10.15628 /$ holos. 2016.3592

\section{RESUMO}

Este artigo foi elaborado a partir de uma pesquisa de mestrado em educação e apresenta a análise de criações artísticas africana e afro-brasileira presentes em livros didáticos de História do Ensino Fundamental, em uma cidade do Triângulo Mineiro, durante o período de 2011 a 2013. As análises das expressões encontradas fundamentaram-se em princípios da pesquisa fenomenológica, segundo Bicudo. Observou-se, nas imagens, a predominância de expressões da arte préhistórica, das máscaras africanas e de imagens que remetem à escravidão, dificultando o trabalho de valorização da identidade, da história e da cultura dos afro-brasileiros. Estudos interdisciplinares com a Arte e a História são, ainda, tênues.

\section{THE UNVEILING OF AFRICA IN ARTISTIC CREATIONS IN HISTORY TEXTBOOKS OF ELEMENTARY SCHOOL}

\begin{abstract}
This article was prepared from a master's research in education and presents the analysis of African and African-Brazilian artistic creations present in History textbooks of the elementary school, in a town of Triângulo Mineiro, during the period 2011 to 2013. The analysis of the expressions found were based on principles of phenomenological research, according to
\end{abstract}

Bicudo. It was observed in the images the predominance of expressions of prehistoric Art, African masks and images that refer to slavery, hindering the appreciation work of identity, history and culture of African-Brazilian. Interdisciplinary studies of Art and History are still tenuous.

KEYWORDS: African and African-Brazilian Art; Textbooks; Elementary School; Interdisciplinarity. 


\section{INTRODUÇÃO}

A análise da arte africana e afro-brasileira em livros didáticos da educação básica, especialmente os de História, foi tomada como um caminho em busca da compreensão das contribuições da cultura africana na formação do povo brasileiro, a qual entendemos ser possível a partir das análises dessas expressões artísticas. Apoiamo-nos, nesse sentido, em reflexões como as de Ferrari (2012, p. 21-22).

[...] em toda obra de arte, seja ela visual, cênica, literária ou musical, há o pensamento do ser humano e sua condição de ser e estar imerso em contextos culturais. Dessa forma, entendemos a arte como um produto do ser humano que lida com uma rede complexa de pensamentos, com relações e modos simbólicos de fazer e expressar leituras de mundo.

Consideramos a arte como conhecimento e as possibilidades de leitura que ela oferece, em uma atitude interdisciplinar adotada durante a pesquisa, em que buscamos, como nos dizeres de Fazenda (2001, p. 69), o nosso "[...] próprio sentido de "ser-no-mundo" através dessas expressões.

A expectativa de nossas buscas foi a de visualizar o que as artes africana e afro-brasileira, presentes nos livros em análise, teriam para nos contar sobre a presença da África na formação do povo brasileiro, uma vez que, conforme Oliveira \& Garcez (2002, p. 19), a arte pode nos levar a interpretar o mundo por trazer em si possibilidades de "provocar emoção e reflexão; expressar o pensamento e a visão de mundo do artista; explicar e refletir a história humana; questionar a realidade; representar crenças e homenagear deuses, ideias, pessoas, entre muitas outras".

Para essa análise, selecionamos obras segundo os critérios de: pertencimento ao Programa Nacional do Livro Didático - PNLD (1985); utilização na disciplina de História no Ensino Fundamental durante o período de 2011 a 2013, triênio que se refere a esse nível de ensino e com abrangência da rede pública de educação básica.

\section{REFERENCIAL TEÓRICO}

$\mathrm{Na}$ busca pelas expressões das artes africana e afro-brasileira nos livros selecionados como corpus da pesquisa, destacou-se a perspectiva interdisciplinar ao considerar o necessário diálogo entre a História e a Arte, e as leituras possíveis e decorrentes desse diálogo. Nesse sentido, Japiassu (1976) e Fazenda (2001) foram autores consultados. Com eles refletimos sobre a minimização das barreiras entre as disciplinas e sobre a atitude interdisciplinar de diálogo, possibilitando inovações e conquistas no ensino.

Quanto às questões da Arte como conhecimento, nossas reflexões estiveram baseadas em considerações de Ana Mae Barbosa. Para essa autora, o potencial da Arte como conhecimento infere-se do fato de que

Por meio da Arte é possível desenvolver a percepção e a imaginação, apreender a realidade do meio ambiente, desenvolver a capacidade crítica, permitindo ao indivíduo analisar a realidade percebida e desenvolver a criatividade de maneira a mudar a realidade que foi analisada. (BARBOSA, 2003, p.18) 
Destacamos ainda a leitura de textos legais que determinam e orientam o estudo de questões étnico-raciais africanas na educação básica, bem como aqueles que orientam as ações do Programa Nacional do Livro Didático - PNLD, considerando que os livros analisados integram esse programa.

Finalmente nossos olhares se voltaram aos textos de Bicudo (2000 e 2012), dada a perspectiva fenomenológica de análise à qual nos propusemos.

\section{PROCESSOS METODOLÓGICOS}

A busca pela presença das artes africana e afro-brasileira em Livros Didáticos da Educação Básica caracterizou-se na abordagem qualitativa em que foi realizada a pesquisa.

Os resultados das buscas apontaram 546 imagens presentes em 43 livros analisados, e realizamos sua análise na perspectiva da questão formulada, qual seja: como se desvelam as artes africana e afro-brasileira nos livros didáticos selecionados como corpus da pesquisa.

Na investigação situada, contextualizada social e culturalmente, lançamos mão do descrito, do desvelado, para, a partir daí, interpretá-lo à luz da experiência vivida e do diálogo realizado com os livros e suas imagens e com as leituras realizadas no decorrer da pesquisa.

Assim, o retorno aos livros didáticos com a intenção de compreender melhor as 546 expressões em análise, foi necessário diversas vezes, sobretudo ao considerarmos que "mostrar-se e esconder-se sob diferentes ângulos de visão é uma característica do fenômeno [...]", como afirmam Bicudo, Baumann e Mocrosky (2011 p. 2). Incluímos no estudo observações pessoais advindas das leituras e das análises, numa dimensão subjetiva de interpretação que também caracteriza a pesquisa fenomenológica.

Dessa perspectiva, delineamos os itinerários investigativos, tendo sempre como horizonte a interrogação formulada: como a arte africana e a arte afro-brasileira são mencionadas nos livros didáticos de História adotados do 6으 ao 9 ano do Ensino Fundamental de escolas da rede pública em um município mineiro?

Conforme o que propõe Bicudo (2000, p. 74):

A investigação fenomenológica trabalha sempre com o qualitativo, com o que faz sentido para o sujeito, com o fenômeno posto em suspensão, como percebido e manifesto pela linguagem: e trabalha também com o que se apresenta como significativo ou relevante no contexto no qual a percepção e a manifestação ocorrem.

Dessa forma, tendo optado por "ir-à-coisa-mesma", propomos quatro unidades de significado, quais sejam: expressões da arte africana, expressões da arte afro-brasileira, expressões sobre o negro no Brasil e expressões de artistas brasileiros com influência africana. Essas unidades caracterizaram a forma de apresentação das expressões artísticas encontradas, para que pudéssemos analisá-las e compreendê-las. 


\section{CARACTERIZAÇÃO DAS ANÁLISES}

Fizeram parte da pesquisa 57 escolas da rede pública do município mineiro de Uberaba, sendo 31 estaduais e 26 municipais.

No triênio escolhido, 2011-2013, as 26 escolas municipais haviam feito opção por adotar apostilas elaboradas por uma instituição do sistema particular de ensino. Dessas apostilas, 15 volumes foram objeto de nossas análises.

Quanto às 31 escolas estaduais, analisamos 28 livros do Programa Nacional do Livro Didático (PNLD).

Ao considerar as unidades de significado, observando e interrogando as 546 expressões encontradas no material da pesquisa, chegamos ao resultado seguinte conforme Tabela 1.

Tabela 1: Expressões artísticas desveladas nos livros didáticos de História do Ensino Fundamental da rede pública de Uberaba, MG (2011-2013).

\begin{tabular}{l|c}
\hline Unidades de Significado & Frequência em que aparecem \\
\hline Expressões da arte africana & 232 \\
\hline Expressões da arte afro-brasileira & 27 \\
\hline Expressões sobre o negro no Brasil & 262 \\
\hline Expressões de artistas brasileiros com influência africana & 25 \\
\hline \multicolumn{1}{c}{ Total } & 546 \\
\hline
\end{tabular}

Fonte: Livros didáticos de História, analisados por Tânia Mára Souza Guimarães, 2015

\subsection{Expressões da arte africana}

Foram encontradas, entre desenhos, xilogravuras, esculturas, máscaras, pinturas, artesanatos em geral, dentre outras, 232 imagens.

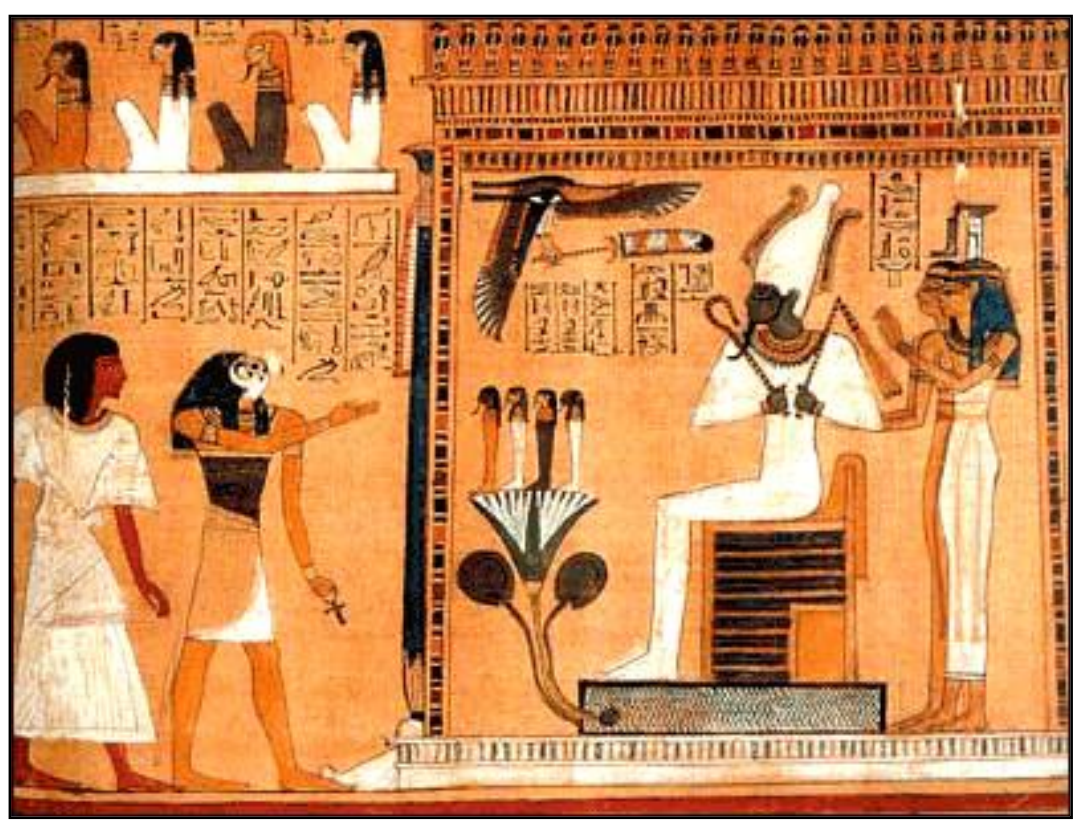

Figura 1: Julgamento diante de Osíris, arte egípcia in Motooka, Para viver juntos, História, 2009. 
A preponderância nessa unidade, das menções feitas às artes, sobretudo egípcia e cuxita, foi destaque. Os egípcios e os cuxitas são povos pertencentes à região norte do continente africano, que compõem a chamada África Branca, cujas influências na formação da identidade do povo brasileiro não são consideradas relevantes, uma vez que os africanos para cá trazidos como escravos pertenciam a outras regiões daquele continente. Apresentamos na Figura 1, um exemplo desse tipo de ilustração.

O cotidiano vivido por pessoas importantes bem como de atividades que ocorriam no entorno de seu dia-a-dia enquanto em vida, conforme se observa na Figura 1, são destacados nas expressões que são contadas nesta unidade de significado.

\subsection{Expressões da arte afro-brasileira}

São manifestações artísticas criadas no Brasil carregadas de características próprias dos negros trazidos para cá como escravos. Entre poesias, textos e contos africanos que estão presentes na literatura brasileira, além de expressões corporais que se revelam em danças, movimentos e estilos musicais, são diversas as expressões que, fazendo parte da cultura do continente africano, vieram fazer parte também do cotidiano e da cultura brasileiros.

Dessa unidade, encontramos 27 expressões no material didático.

Consideramos interessante mencionar aqui a construção de templos por irmandades negras do tempo da escravidão. Sua iniciativa em construir seus locais de adoração se deu em razão de não Ihes ser permitido, à época, adentrar quaisquer templos frequentados por pessoas brancas. Consideramos digna de menção a atitude desses negros que, embora escravos continuassem livres em suas aspirações espirituais.

Nesse sentido, é destaque em um dos livros analisados, a imagem de uma mesquita em Porto Novo, Benin, que teve sua arquitetura inspirada em igreja de Salvador, BA, que, à época da escravidão, foi construída por escravos.

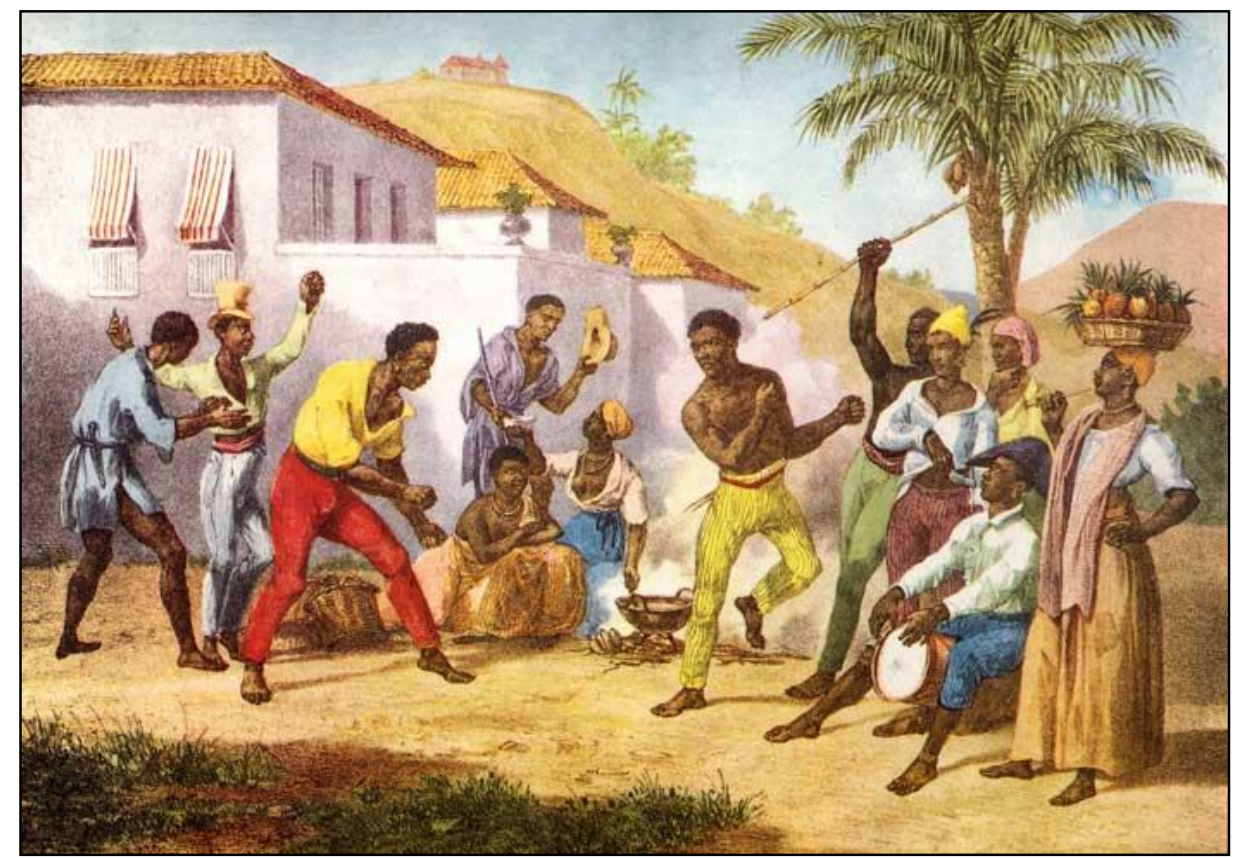

Figura 2: Capoeira, Johann Moritz Rugendas in Nemi e Barbosa, Para viver juntos, História, 2009. 
Parte das expressões integrantes dessa unidade de significado, embora de forma quantitativamente inexpressiva ao se considerar o total de menções em todas as unidades, ou seja, apenas 14 em 546, faz alusão ao samba, à capoeira, ao congado e ao maracatu. Na Figura 2 apresentamos a imagem da capoeira tal como apresentada em um dos livros pesquisados. Segundo Nemi e Barbosa (2009), a capoeira era dança e luta ao mesmo tempo e servia de diversão e de defesa, tendo sido desenvolvida no Brasil pelos africanos escravizados e por seus descendentes.

Essa importante expressão cultural afro-brasileira, conforme se lê em outro dos livros analisados, é reconhecida tanto no Brasil quanto no exterior (BOULOS JÚNIOR, 2009, p. 19).

\subsection{Expressões sobre o negro no Brasil}

Entre telas, gravuras, desenhos, fotos, esculturas e outros, as expressões sobre o negro no Brasil são maioria no material analisado.

São 262 imagens, representando 47,98\% de todas as 546 expressões encontradas de vários artistas que, com suas pinturas, litografias, fotografias, filmes, desenhos, aquarelas e outros, retrataram diversas situações do cotidiano dos negros no País, destacando-se nessas expressões a alusão à escravidão.

Algumas das obras de Jean-Baptiste Debret, um artista parisiense que esteve no Brasil à época da escravidão, estão presentes em 68 das 262 imagens incluídas nessa unidade de significado. Destacamos a seguir na Figura 3, a tela 'Jantar no Brasil', que aparece seis vezes nos livros analisados.

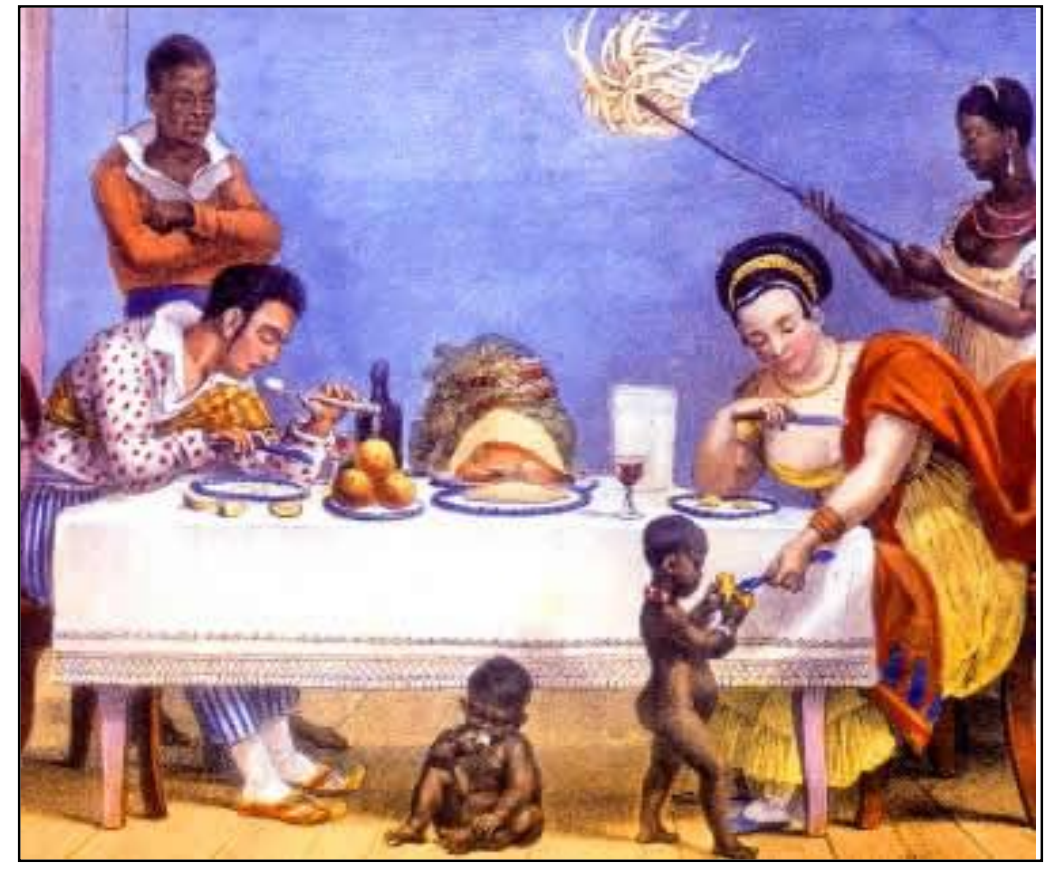

Figura 3: Jantar no Brasil, Jean-Baptiste Debret in Cardoso, Tudo é História. História do Brasil (séculos XIX-XX), 2011.

Outro nome que se destaca nesta unidade de significado é o de Johann Moriz Rugendas, um artista alemão que também esteve por um tempo no Brasil. Rugendas teve seus trabalhos ilustrando os livros de História analisados, em um total de 59 obras. A Figura 4 foi parte dessas obras mencionadas. 


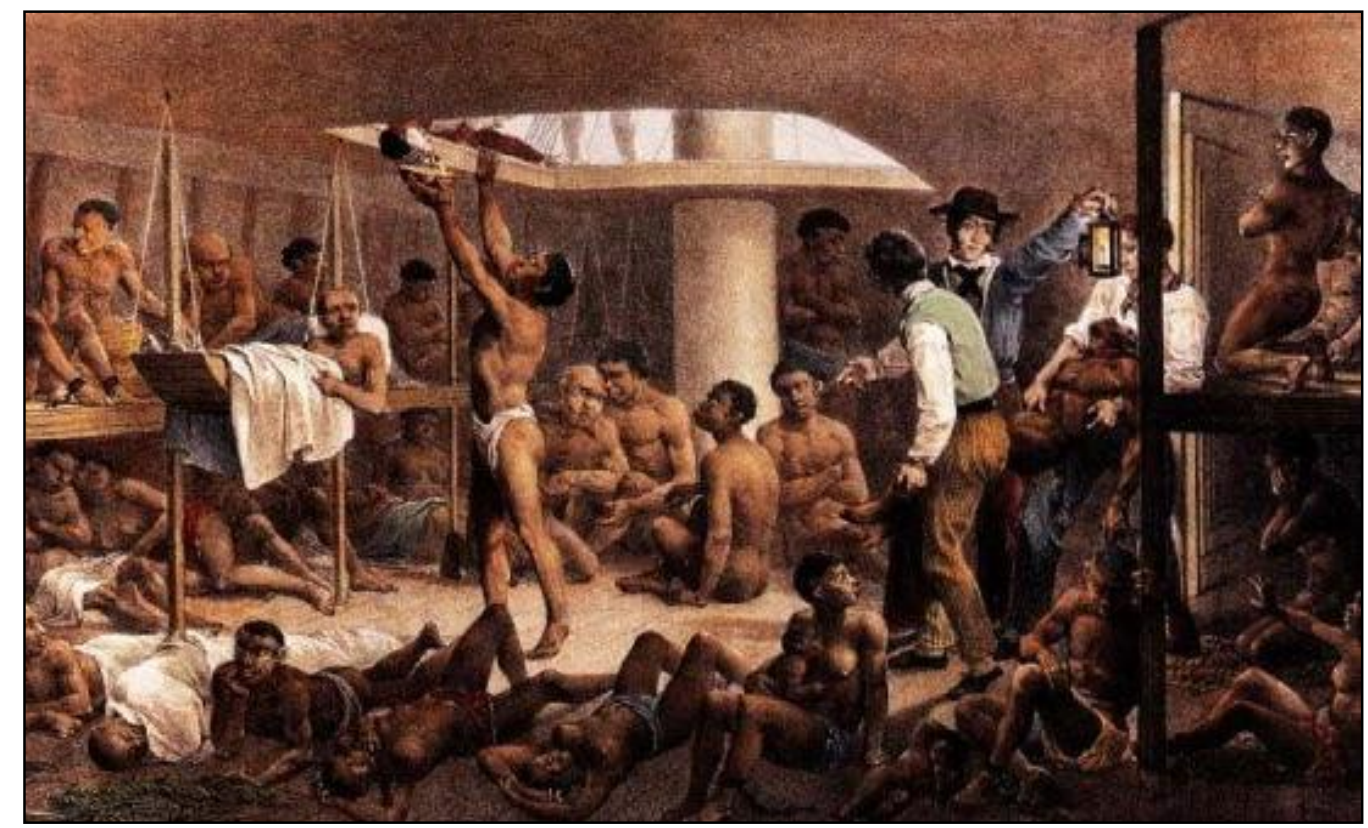

Figura 4: Negros no porão do navio, 1835 - Johann Moritz Rugendas in Piletti, Piletti e Tremonte, História e Vida Integrada, 2011

Das 262 expressões que fizeram parte dessa unidade de significado, 12 não tiveram seus autores identificados. Do restante, encontramos obras de 40 artistas dos quais destacam-se, além de Debret e Rugendas, embora com apenas um total de 12 imagens, os artistas Cândido Portinari, Di Cavalcanti e Tarsila do Amaral.

Em todos eles, como observamos nas obras de Debret e Rugendas, percebemos a predominância da menção ao cotidiano escravo dos negros que para cá foram trazidos contra a sua vontade.

Lembramos que

Não podemos perder de vista que muitos materiais didáticos têm desempenhado um papel muitas vezes decisivo na introjeção de conceitos errados, de forma velada ou explícita, assim como de estereótipos. Vejamos alguns exemplos: não se pode mais aceitar a difusão da escravidão como fato que se associa exclusivamente aos povos africanos, nem tampouco imagens do negro apenas como escravos ou no desempenho de atividades na sociedade sem prestígio; de não inserir devidamente o papel do negro brasileiro nos ciclos econômicos do país; de não revelar o contingente populacional de afro-descendentes atual no Brasil e sua importância; enfatizar que os africanos e seus descendentes são, também, responsáveis pela adequação aos trópicos da tecnologia pré-capitalista brasileira, como a mineração, a medicina, a nutrição e a agricultura; que a herança cultural trazida da África constitui a matriz mais importante da cultura popular brasileira e que é frequentemente relegada pela ideologia dominante ao folclore (ANJOS apud MUNANGA, 2005. p. 177).

Pensamos que essa ênfase na escravidão não contribui para a compreensão de nossa identidade. 


\subsection{Expressões de artistas brasileiros com influência africana}

Nessa unidade, relacionamos 25 expressões no total, sendo 18 de Antônio Francisco Lisboa (Aleijadinho), três de Manuel da Costa Ataíde (Mestre Ataíde), uma de Djanira Motta Silva, uma de Deoscóredes Maximiliano dos Santos (Mestre Didi) e duas de Valentim da Fonseca e Silva (Mestre Valentim).

Aleijadinho (1738-1814) se destaca como escultor, entalhador e arquiteto, Mestre Ataíde (1762-1830), como pintor e decorador, Djanira Motta Silva (1914-1979) como pintora, ilustradora, cartazista, cenógrafa e gravadora, Mestre Didi (1917-2013) como escritor, artista plástico e sacerdote afro-brasileiro, e Mestre Valentim (c. 1745-1813) como escultor, entalhador e urbanista.

A originalidade das obras de Aleijadinho, conforme percebe-se na Figura 5, leva-nos a considerações sobre a força expressionista e os detalhes geométricos que se fazem presentes também em expressões da arte africana.

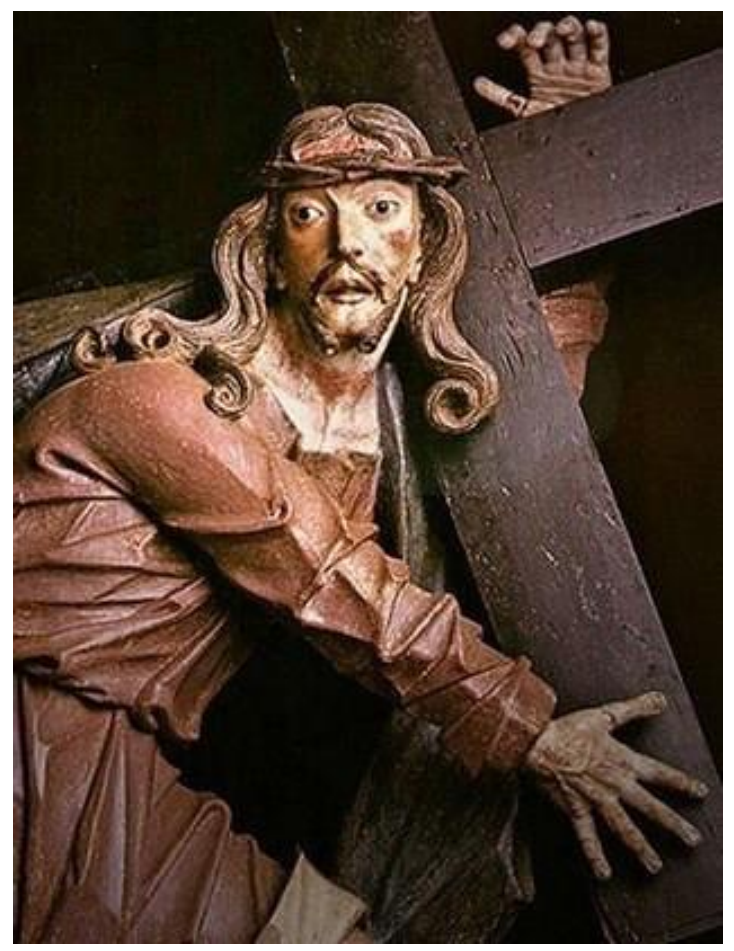

Figura 5: Detalhe da obra - O Cristo carregando a cruz, Aleijadinho in BOULOS JÚNIOR, História, sociedade \& cidadania, 8 ano. 2009.

Destacamos que, a não ser por considerações que aparecem mencionadas nas obras de Djanira Motta e Silva e de Mestre Didi, nos livros analisados não se faz qualquer outra menção escrita à influência africana recebida pelos artistas relacionados nesta unidade de significado, muito embora a leitura de alguns documentos que fizeram parte da pesquisa ora relatada traga considerações relevantes sobre tal influência.

\section{PALAVRAS FINAIS}

Percebe-se que as artes africana e afro-brasileira não ocupam um espaço considerável nas páginas dos 43 livros analisados. As expressões das artes egípcias, cuxitas e de outros povos 
africanos de tempos remotos, além das expressões que destacam as questões de escravidão, aparecem de forma relevante no material analisado.

O reconhecimento e a valorização da identidade, da história e da cultura afro-brasileiras se encontram, em termos gerais, precariamente obedecidos.

As artes e os artistas africanos da atualidade não são mencionados e o excesso de representações de situações de escravidão enfrentadas pelos negros no País dificultam o trabalho de valorização da identidade e do reconhecimento de igualdade que estão legalmente estabelecidos. Embora a Nação brasileira tenha vivido uma história de séculos de escravidão, as referências e imagens desse triste fato de nossa história não esclarecem o valor da presença dos africanos no Brasil, nos mais diversos aspectos.

Cabe, certamente, a continuidade dos estudos ora apresentados, com outras análises e outros olhares às expressões artísticas presentes nos livros didáticos. Seria oportuno, por exemplo, considerar que tipo de reflexões as imagens analisadas provocaram nos alunos do 60 ao 9 음 ano, aos quais os livros da presente pesquisa estiveram destinados. Dividimos com o leitor o prosseguimento desse tipo de investigação.

Esperamos que as considerações ora realizadas possam de alguma forma, contribuir com o estudo étnico-racial que precisa ser realizado dentro das escolas brasileiras e que a sensibilização dos alunos em relação à arte africana e afro-brasileira presente nos livros didáticos possa ser aguçada a partir de um ensino consciente não só de História, mas também da própria arte em um trabalho interdisciplinar.

\section{REFERÊNCIAS BIBLIOGRÁFICAS}

1. ANJOS, R. S. A. dos. A Geografia, a África e os Negros Brasileiros. In MUNANGA, K. (Org.). Superando o racismo na escola. 2. ed. revisada / - Brasília: Ministério da Educação, Secretaria de Educação Continuada, Alfabetização e Diversidade, 2005. 204 p.: il. Disponível em: <http://portal.mec.gov.br/secad/arquivos/pdf/racismo_escola.pdf> Acesso em: 10 set. 2014.

2. BARBOSA, A. M. (Org.) Inquietações e mudanças no Ensino da Arte. São Paulo: Cortez, 2003.

3. BICUDO, M. A. V. Fenomenologia: confrontos e avanços. São Paulo: Cortez, 2000.

4. _. A pesquisa em educação matemática: a prevalência da abordagem qualitativa. Revista Brasileira de Ensino de Ciência e Tecnologia, v. 5, n. 2, p. 15-26, maio-ago. 2012. Disponível em: <http://periodicos.utfpr.edu.br/rbect/article/view/1185> Acesso em 17 nov. 2013.

5. BICUDO, M. A. V.; BAUMANN, A. P. P.; MOCROSKY, L. F. Análise fenomenológica de projeto pedagógico. In: CONGRESSO DE FENOMENOLOGIA DA REGIÃO CENTRO-OESTE, 4, 2011, Goiânia. Anais eletrônicos... Goiânia: UFG, 2011. p. 157-166.Disponível em: <http://anaiscongressofenomenologia.fe.ufg.br/up/306/o/ComunMariaViggianiBicudo.pdf> Acesso em: 14 nov. 2014.

6. BOULOS JÚNIOR, A. História, sociedade \& cidadania, 8o ano. São Paulo: FTD, 2009.

7. BRASIL. Decreto no 91.542, de 19 de agosto de 1985. Institui o Programa Nacional do Livro Didático, dispõe sobre sua execução e dá outras providências. Disponível em: <http://www2.camara.leg.br/legin/fed/decret/1980-1987/decreto-91542-19-agosto-1985441959-publicacaooriginal-1-pe.html> Acesso em: 10 dez. 2014. 
8. CARDOSO, O. P. Tudo é História. História contemporânea. História do Brasil (séculos XIX-XX), 8o ano. São Paulo: Ática, 2011.

9. FAZENDA, I. C. A. Inderdisciplinaridade: História, teoria e pesquisa. 8. ed. São Paulo: Papirus, 2001.

10. FERRARI, S. S. U. Encontros com arte e cultura, 1. ed. São Paulo: FTD, 2012.

11. JAPIASSU, H. Interdisciplinaridade e Patologia do Saber. Rio de Janeiro: Imago,1976.

12. MOTOOKA, D. Y. Para viver juntos, História, 6ำ ano. São Paulo: Edições SM, 2009.

13. NEMI, A. L. L.; BARBOSA, M. Para viver juntos, História. 7ํano. São Paulo: SM, 2009.

14. OLIVEIRA, J.; GARCEZ, L. Explicando a arte: uma iniciação para entender e apreciar as artes visuais. 4. ed. Rio de Janeiro: Ediouro, 2002.

15. PILETTI, N.; PILETTI, C.; TREMONTE, T. História e vida integrada, 7ํano. 4. ed. São Paulo: Ática, 2011. 